\title{
Outcomes and Factors Affecting HIV Status Disclosure to Regular Sexual Partner among Women Attending Antiretroviral Treatment Clinic
}

\author{
Bedilu Deribe $^{1 *}$, Jemal Ebrahim ${ }^{1}$ and Lema Bush ${ }^{2}$ \\ ${ }^{1}$ Hawassa University School of Nursing and Midwifery, Ethiopia \\ ${ }^{2}$ Hawassa University Comprehensive Specialized Hospital, Hawassa Ethiopia
}

\begin{abstract}
Introduction: HIV infected individuals face a number of challenges when they disclose their sero-status. Although discloser improves access to HIV prevention, increased opportunities for risk reduction and increased opportunities to plan for the future, HIV positive status discloser is lower in developing countries.
\end{abstract}

Objective: To assess outcomes and factors affecting HIV status discloser to regular sexual partner among women attending anti-retroviral treatment clinic at Hawassa university comprehensive specialized hospital.

Method and materials: An institution based cross sectional study was conducted among 191 randomly selected HIV positive women attending Hawassa university referral hospital ART Clinic from Mar 1 -Mar 30 in 2017. The data was collected after having ethical clearance letter from institutional review board and consent from client. Data were collected through interview using pre-tested questioners. The collected data was analyzed by using SPSS version 20. Bivariate and multivariate logistic regressions were done and final significantly associated factors were identified on the basis of OR with $95 \% \mathrm{Cl}$.

Results: over all 72.9 of the women has disclosed their HIV status to sexual partners. Among those disclosed their HIV positive status, $54.1 \%$ get their freedom to have follow up. While $30 \%$ get their freedom to use condom. Negative outcomes associated with status disclosure were stigma $11.6 \%$, discrimination $10.1 \%$ and psychological violence $5 \%$.Women who had rough relation with her $89 \%$ less likely to disclose their status as compared to women with smooth relationship $(A O R=0.11955 \mathrm{Cl} 0.01,0.119)$. Women who had children were 9.89 times more likely to disclose their status to sexual partners than their counter parts (AOR 9.89, 95\% Cl 2.68, 36.36).women who received counseling were almost 7 times more likely disclose their HIV status to their sexual partner (AOR=5.63 95\% $\mathrm{Cl} 2.24,14.13)$.

Conclusion: HIV positive status discloses to sexual partners was found to be low.HIV status disclosure was accompanied by both negative and positive consequences. Presence of offspring, counseling, relationship status before status disclosure was factors associated with HIV positive status disclosure.

Keywords: Outcome; HIV status disclosure; Hawassa

\section{Introduction}

Discloser is a process one that positively linked to concealing care and support. Disclosure of HIV status to sexual partner is in important prevention goals emphasized by the WHO and the centres for disease control and prevention discloser offers a number of important benefit to the infected individuals and to the general public in addition HIV status discloser may lead to improve access to HIV prevention and treatment programs increased opportunities for risk reduction and increased opportunities to plan for the future [1]

Studies indicate that HIV positive status disclosure among HIV positive women ranges from $49 \%$ in Jamaica to $98.5 \%$ in Tanzania [2-8]. In Ethiopia too HIV positive statues disclosure rate varies from place to place. Similarly, local studies carried out in Gore and Mettu 69\%, Jimma 94.5\%, Axum 80.1\%, Gonder 89.7 \&, Asela $94.1 \%$ as well as Addis Ababa 92\% [9-14].

Discloser may have lifelong implications since more people are living longer and often asymptomatically with HIV in reality some HIV persons may choose not to disclose due to fear of rejection or harm. Feeling of shame, desire to maintain secretly, felling with safer sex there is no need for discloser; fantasize perceived community norms against discloser and beliefs that individuals are responsible for protecting themselves [15]. A lot of HIV-positive individuals need to share information about their HIV status with their partners. However the circumstances and timing often vary. Whilst some people are able to tell their sexual partners immediately, others may hold back because of concerns about potential negative consequences. Some HIV- positive people may be reluctant to disclose whilst trust is still developing in relatively new relationships [16-18].

Disclosure is something that every person living with HIV experiences and struggles with. The process is complex and fraught with mixed emotions, and the outcomes can be unpredictable and difficult to handle. Despite the difficulty disclosure might pose, nondisclosure has detrimental impacts on the person living with HIV and is associated with personal distress, loneliness and social isolation. Furthermore, non-disclosure may lead to medical non-adherence as a way to conceal the disease from others Not only is disclosure important for the person living with HIV, it is also important for those around him or her [19-22].

*Corresponding author: Bedilu Deribe, Hawassa University School of Nursing and Midwifery, Ethiopia, Tel: 251927108065; E-mail: bediluderibe2002@gmail.com

Received January 06, 2018; Accepted February 26, 2018; Published March 05, 2018

Citation: Deribe B, Ebrahim J, Bush L (2018) Outcomes and Factors Affecting HIV Status Disclosure to Regular Sexual Partner among Women Attending Antiretroviral Treatment Clinic. J AIDS Clin Res 9: 760. doi: 10.4172/2155-6113.1000760

Copyright: (C) 2018 Deribe B, et al. This is an open-access article distributed unde the terms of the Creative Commons Attribution License, which permits unrestricted use, distribution, and reproduction in any medium, provided the original author and source are credited. 
For many individuals, disclosure helps them gain higher levels and better quality of social support $[19,23,24]$. However, in contexts where there is a high level of stigma, the association between disclosure and social support is weaker. Social support can be emotional or practical: emotional support includes expressions of concern and acceptance, and practical support includes financial or housing support and assistance with medical visits [24].

In the context of society and community, disclosure is thought to be important for public health purposes in terms of preventing the spread of HIV. Furthermore, non disclosure of one's HIV-positive status before engaging in a sexual act can lead to criminal prosecutions in Canada and elsewhere. Given the personal, societal and legal importance of HIV disclosure, it is important to understand the experiences of HIV disclosure, as well as effective disclosure strategies and interventions for people living with HIV. Therefore, the main intention of this study was to assess factors that influence HIV positive women's status disclosure in Hawassa university referral hospital. Besides we focused on determine the outcome of HIV positive status discloser to sexual partners in Hawassa referral hospital. Besides we focused on determine the outcome of HIV positive status discloser to sexual partners in Hawassa referral in hospital.

\section{Methodology}

\section{Study design}

A cross sectional study was carried out among women attending ART care service at Hawassa referral hospital.

\section{study area and period}

Hawassa referral hospital was established in 1996 E.C. The hospital is found in southern part of Hawassa town. It provide diversity of both inpatient and outpatient service for about 18 million population from all over SNNPR and neighbour region Oromia it offers service at general and specialty levels including internal medicine paediatrics and child health, surgery, gynecology and obstetrics, ENT, neurology, urology, psychiatric, ophthalmology, dermatology, dentistry, radiology, pathology, laboratory and pharmacy service. ART clinic begin to give service in 1997. Currently give service for 2356 HIV positive women it gives sercice such as ART follow up and prevention care at pre ART clinics, ART drugs and follow up at ART clinics. This study was conducted Mar 1-Mar 30, 2016.

\section{Populations}

Source population: HIV positive women, attending ART clinic of Hawassa university comprehensive specialized hospital

Study population: All HIV positive women who has regular sexual partner and attending their ART follow up at Hawassa university referral hospital ART clinic.

Study unit: All HIV positive women who have regular sexual partner and attending Hawassa university referral hospital ART clinic, who are presented during data collection, give informed consent and greater or equal to 18 years were used as sample population.

\section{Inclusion and exclusion criteria}

Inclusion criteria: HIV positive women who had regular sexual partners, at least 18 years of age and an able to give informed consent and started taking antiretroviral drug.

Exclusion criteria: The Study does not include women who are unable to hear, and unable to give informed consent.

\section{Sampling}

Sampling size: The sample size will be determined by using the general formula for estimating single population proportion with the following assumption, $\mathrm{p}=85.7 \%$ proportion from previous study, $\mathrm{d}=0.05$ and $95 \%$ CI.

\section{Formula}

$\mathrm{n}=\left(\mathrm{z}(\alpha / 2)^{2} \mathrm{p}(1-\mathrm{p})\right) / \mathrm{d}^{2}$

Where,

$\mathrm{n}=$ minimum sample size

Alpha=level of significance

$\mathrm{Z}=$ the standard normal variable or deviate, alpha was 0.05 with $95 \%$ confidence interval $\mathrm{p}=$ population proportion estimate (prevalence of HIV status discloser) $\mathrm{d}=$ =margin of error

$$
\begin{aligned}
& \mathrm{p}=0.857() \\
& 1-\mathrm{p}=1-0.857=0.143
\end{aligned}
$$

Alpha $=5 \%$ error, $\mathrm{d}=0.05, \mathrm{z}=1.96$

Considering non-response rate of $10 \%$ the total sample size become 207.

Sampling technique: Sampling frame was prepared based on the patients ART registration number. Following that Systematic random sampling technique was employed to reach the respective study population.

\section{Variables}

Dependent variables: HIV status disclosure

Independent variables

- Age

- Educational background status

- Ethnicity

- Demographic status,

- Religion

- Socio-economic variables.

- Economic dependability on husband

- Previous domestic violence

- Living with extended family

- Participation in MSG service or any support group

- Discussion prior to HIV test with sexual partner

- Duration of relationship with partner

- Partner back ground

- Occupation

- Years of marriage life

The data were collected using structured and pretested questionnaires. The questionnaires were first be prepared in English, translated to local language (Amharic) and then back to English form consistence. The pre-test was done at Adare hospital on 5\% of sample size ( 10 women) at ART clinic who have sexual partners and started the 
treatment. Internal consistencies were checked using chrombach alpha ant it was found to be 0.78 .The collected data was checked manually for its completeness. After this the data was coded and entered to epidata version 3.1 and then it was exported to SPSS version 16.0. Before the actual data analysis the data was explored for its completeness, outliers and missing values. Following data exploration descriptive statistical analysis was done for variables such as Sociodemographic characteristics and clinical factors. For identification of independent variables which have association with the dependent variable, chisquare test and student $\mathrm{t}$-test was used. All factors with $\mathrm{p}<025$ in the univariate analysis were considered as candidates for the multivariate regression model. The $95 \%$ confidence interval (CI) was calculated wherever found appropriate. P-value less than 0.05 of the multivariate analysis were considered significant factors.

The study will be conducted after ethical letters obtained from Hawassa university ethical review committees. Then data will be collected after informed and written consent was taken to keep the confidentiality, the participants name will not be written and unauthorized person will not having access to data .

\section{Operational Definitions}

Outcome: The consequence that HIV positive women face after disclosure of her HIV positive status her sexual partners.

Extended family: Is a family that extends beyond the nuclear family, consisting of aunts, uncles and cousins all living nearby or in the same house hold.

Domestic violence: Is the willful intimidation, physical assaults and other abusive behaviors as part of systematic pattern of power and control per pretended by one intimate partner against another including physical violence, psychological violence and emotional abuse.

Discloser: In the context of HIV/AIDS discloser refers to the act of informing any individual about HIV status of an infected person or, that such information has been transmitted by any means, by the person him or herself with or without consent.

HIV status: The presence or absence of antibody for HIV antigen, positive means exposed or has the virus in her blood.

Regular sexual partner: A partner refers to two people who have sex together e.g. husband and wife, boyfriend and girlfriend, a regular sexual partner refers to a partner who has sexual regularity as a couple or husband and wife.

\section{Result}

A total of 207 women were interviewed $82.1 \%$ of women were urban area, in terms of population number dominate ethnics group were sidama (36.7\%), the mean age was 36.19 year, the majority of women attends $32.9 \%$ primary school and $28.5 \%$ able to read and write, most of women had greater than or required to 800 birr income (53.6\%), regarding their marital status $86 \%$ were married and $53.6 \%$ women were house wife.

\section{HIV status disclosure}

As can have been seen from Figure 1, out of 207 respondents, 151 (27.9) of them had disclosed their status results to their partners, whereas about 56 (27.1\%) of them did not disclosed.

Outcome of status disclosure: Regarding the outcome among those disclosed their HIV positive status, $54.1 \%$ get their freedom to have follow up. While $30 \%$ say it give their freedom to used condom.

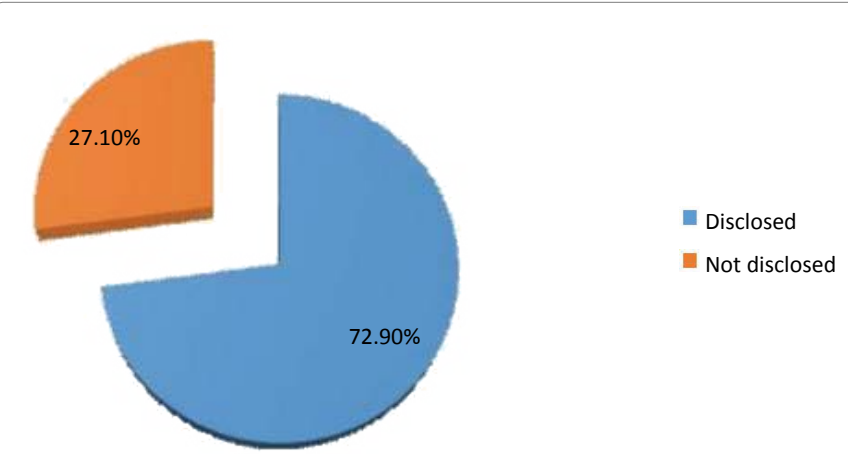

Figure 1: Status disclosure of women to their sexual partner at ART clinic, HwURH, 2008 E.C.

Those outcomes with negative effect were stigma $11.6 \%$, discrimination $10.1 \%$ and psychological violence $5 \%$.

Factors associated to HIV positive status disclosure: Women who received counseling on how to disclose HIV status were almost 6 times more likely to disclose as compared to women did not received counseling on how to disclose. This means the contribution of counseling for disclosing their status to the partner is important for women on ART in the study area. Women who had offspring have also positive association with HIV status disclosure. The odds disclosing HIV status is almost 8 times among those who have children as compared to those who have no children. Women who know their sexual partners HIV status before were 13.48 ( $\mathrm{AOR}=13.4,95 \% \mathrm{CI} 4.11,36.16)$ times more likely to disclose their status as compared to those women who do not know their sexual partners HIV status.

Furthermore, the relationship before HIV test has positive association with HIV status discloser. Women, who had disagreement and rough relationship with their sexual partner before HIV testing were $89 \%$ less likely to disclose their status as compared to women who have smooth relationship.

Women who stayed on ART for more than one year were $78 \%$ less likely to disclose their HIV positive status as compared to women who were taking ART for less than one year (AOR=0.22 95\% CI 0.049 , 0.983). Considering all other factors constant females who were out of the reproductive age group were $63 \%$ less likely to disclose their HIV status as compeered women in reproductive age group (COR 0.37 (95\% CI 0.0142, 0.966)) (Table 1 and Table 2).

\section{Discussion}

The proportion HIV positive status discloser of our study area is lower than that of other developing countries [2-4,8]. Our study finding was lower than study conducted in Jimma, Axum, Gonder and Asela as well as Addis Ababa [10-14]. The finding of this study is lower than that of study done in similar setting $(87.7 \%) 6$ years back this variation might be difference in sample size, difference in population characteristics. This variation may be attributable to sociodemographic and slight cultural variation of the study areas as well as current weakening of HIV awareness creation throughout the country. The findings of our study warn the need for sustained and persistent mobilization on the benefits of disclosure related to HIV prevention and control. The disclosure rate in this finding might have positive implication in prevention of HIV infection of sexual partners of sero-discordant status, prevention mother to child transmission, prevention of re-infection of new strain of the HIV/AIDS, motivated sexual partners to VCT and practice safe 
Page 4 of 5

\begin{tabular}{|c|c|c|}
\hline Variable(n=2007) & Number & Percent \\
\hline \multicolumn{3}{|l|}{ Age in years } \\
\hline $18-24$ & 4 & 1.9 \\
\hline $25-31$ & 67 & 32.2 \\
\hline $32-38$ & 74 & 35.7 \\
\hline $39-45$ & 16 & 7.7 \\
\hline$>45$ & 46 & 22.2 \\
\hline \multicolumn{3}{|l|}{ Religion } \\
\hline Orthodox & 94 & 45.4 \\
\hline Protestant & 95 & 45.9 \\
\hline Catholic & 9 & 4.3 \\
\hline Muslim & 9 & 4.3 \\
\hline \multicolumn{3}{|l|}{ Others } \\
\hline \multicolumn{3}{|l|}{ Marital status } \\
\hline Married & 178 & 86 \\
\hline Have sexual partner & 15 & 7.2 \\
\hline Divorced & 8 & 3.9 \\
\hline Widowed & 6 & 2.9 \\
\hline \multicolumn{3}{|l|}{ Education } \\
\hline Do not write and read & 31 & 15 \\
\hline Read and write & 59 & 28.5 \\
\hline Primary & 68 & 32.9 \\
\hline secondary & 20 & 9.7 \\
\hline TVAT & 12 & 5.8 \\
\hline Diploma & 12 & 5.8 \\
\hline Degree and above & 5 & 2.4 \\
\hline \multicolumn{3}{|l|}{ Occupation } \\
\hline House wife & 109 & 52.7 \\
\hline Merchant & 53 & 25.6 \\
\hline Daily labor & 27 & 13 \\
\hline Govt. employer & 8 & 3.9 \\
\hline Private employer & 4 & 1.9 \\
\hline Student & 6 & 2.9 \\
\hline Residence & & 82.1 \\
\hline Urban & 170 & 17.9 \\
\hline Rural & 37 & \\
\hline \multicolumn{3}{|l|}{ Monthly income( in birr) } \\
\hline$<200$ & 13 & 6.3 \\
\hline $200-500$ & 27 & 13 \\
\hline $501-800$ & 56 & 27.1 \\
\hline$>801$ & 111 & 53.6 \\
\hline
\end{tabular}

Table 1: Socio-demographic characteristics of women attending ART clinic, HwURH, 2008 E.C.

sex.

The finding of this study confirms that women who disclose their status to sexual partners experience negative outcomes such as discrimination, stigma, and rejection. Most common reasons raised for non disclosure were fear of discrimination, fear of stigma, fear of psychological violence; fear of physical violence the same as other studies. This may be due to the fact the main rout of the disease transmission is societal taboo, unprotected sexual intercourse. Besides the disease is non curable. This implies that there is need for intense work in creating awareness about the impact of stigma and discrimination against HIV/ AIDS. This is supported by other studies [14,17].

Concerning factors that determine HIV status discloser to their sexual partners, the present study identified relationship of women with their partners before HIV test as one significant factor related to status disclosure. The present study revealed that women in rough relationship were less likely to disclose their status and they were more

\begin{tabular}{|c|c|c|c|c|c|}
\hline \multirow{2}{*}{\multicolumn{2}{|c|}{ Variables $(n=207)$}} & \multicolumn{2}{|c|}{$\begin{array}{c}\text { Status } \\
\text { disclosure }\end{array}$} & \multirow{2}{*}{\begin{tabular}{|c|} 
COR $(95 \% \mathrm{Cl})$ \\
1
\end{tabular}} & \multirow[t]{2}{*}{ AOR $(95 \% \mathrm{Cl})$} \\
\hline & & & & & \\
\hline \multirow{4}{*}{$\begin{array}{l}\text { Educational } \\
\text { status }\end{array}$} & $\begin{array}{c}\text { Do not read and } \\
\text { write }\end{array}$ & \begin{tabular}{|c|} 
Yes \\
27
\end{tabular} & $\begin{array}{c}\text { No } \\
4\end{array}$ & & \\
\hline & $\begin{array}{l}\text { Read and } \\
\text { write }\end{array}$ & 45 & 14 & $0.48(0.14,1.60)$ & \\
\hline & Primary & 35 & 33 & $\begin{array}{c}0.16 \\
(0.05,0.50)^{*}\end{array}$ & \\
\hline & $\begin{array}{l}\text { Secondary and } \\
\text { above }\end{array}$ & 44 & 5 & & \\
\hline Monthly & $<800$ & 77 & 19 & 1 & \\
\hline income & $>801$ & 37 & 74 & $\begin{array}{c}0.49 \\
(0.261,0.935)^{*}\end{array}$ & $\begin{array}{c}0.217 \\
(0.075,0.625)^{\star *}\end{array}$ \\
\hline How status & Mandatory & 142 & 46 & 1 & \\
\hline was known & Self interest & 9 & 10 & $\begin{array}{c}0.29 \\
(0.112,0.761)^{*}\end{array}$ & \\
\hline Duration after & $<1$ year & 52 & 15 & 1 & \\
\hline \multirow[t]{3}{*}{ knowing status } & $\begin{array}{l}1-2 \\
\text { year }\end{array}$ & 32 & 17 & $\begin{array}{c}0.54 \\
(0.24,1.24)\end{array}$ & \\
\hline & $\begin{array}{l}\text { 3-4 } \\
\text { year }\end{array}$ & 55 & 9 & $\begin{array}{c}1.76 \\
(0.71,4.38)\end{array}$ & \\
\hline & $\begin{array}{l}>4 \\
\text { year }\end{array}$ & 12 & 15 & $\begin{array}{c}0.23 \\
(0.09,0.60)^{*}\end{array}$ & \\
\hline Relationship & Smooth & 145 & 46 & 1 & 1 \\
\hline before HIV test & Rough & 6 & 10 & $\begin{array}{c}0.03 \\
(0.01,0.25)^{*}\end{array}$ & $\begin{array}{c}0.11 \\
(0.01,0.119)^{\star *}\end{array}$ \\
\hline \multirow{2}{*}{$\begin{array}{l}\text { Duration on } \\
\text { ART }\end{array}$} & $<1$ year & 72 & 21 & 1 & \\
\hline & $>1$ year & 79 & 36 & $\begin{array}{c}0.658 \\
(0.351,1.234)\end{array}$ & $\begin{array}{c}0.22 \\
(0.049,0.983)^{\star *}\end{array}$ \\
\hline \multirow[t]{2}{*}{ Having children } & No child & 26 & 32 & 1 & 1 \\
\hline & $\begin{array}{l}\text { Have child/ } \\
\text { children }\end{array}$ & 125 & 24 & $\begin{array}{c}6.41 \\
(3.27,12.62)^{\star}\end{array}$ & $\begin{array}{c}9.89(2.63 \\
36.36)^{\star \star}\end{array}$ \\
\hline \multirow{2}{*}{$\begin{array}{l}\text { Knowing } \\
\text { partner's HIV } \\
\text { status }\end{array}$} & Know & 114 & 17 & $\begin{array}{c}7.06 \\
(3.57,13.95)^{\star}\end{array}$ & $\begin{array}{c}13.4 \\
(4.16,36.16)^{\star *}\end{array}$ \\
\hline & Do not know & 37 & 39 & 1 & \\
\hline \multirow{2}{*}{$\begin{array}{l}\text { Getting } \\
\text { counseling }\end{array}$} & Counseled & 98 & 18 & $\begin{array}{c}3.9 \\
(2.03,7.50)^{*}\end{array}$ & $\begin{array}{c}5.63 \\
(2.24,14.13)^{\star *}\end{array}$ \\
\hline & Not counseled & 53 & 38 & 1 & \\
\hline \multirow{2}{*}{$\begin{array}{l}\text { Status after } \\
\text { disclosure }\end{array}$} & Divorced & 30 & 25 & 1 & \\
\hline & Leave together & 121 & 31 & $\begin{array}{c}3.25 \\
(1.68,6.30)^{*}\end{array}$ & \\
\hline \multirow[t]{2}{*}{ Age } & $<49$ years & 141 & 47 & 1 & \\
\hline & Over 49 & 10 & 9 & $\begin{array}{c}0.37 \\
(0.142,0.966)^{*}\end{array}$ & \\
\hline
\end{tabular}

Table 2: Factors affecting HIV positive status disclosure to regular sexual partner among women attending ART clinic, HwUCSH, 2008 E.C.

prone for disclosure related negative consequences like violence and stigma. The most likely reason behind this may be women confidence with their relationship. If a woman is confident of her relationship she may not keep secrets from her partner. This study was not in line to study done in [18].

According to our finding elder women were less likely to disclose their HIV positive status. This finding is in line with study done in morocco and Tanzania [16]. This may be due to social taboo within the study area. The society conceders elder women as social leaders and negotiators besides they were one of respected peoples in the community because of this social influence they may not be willing to disclose their HIV positive status.

Unlike other studies, age of sexual partners, education, socio economic status and income were not significantly associated with HIV positively status discloser. This may be due to variation in study setting and study design. 
Though this is the second study to identify the HIV status disclosure and associated factors with their outcome of status disclosure using Interview administered questioner it has certain limitations it would have been better if prospective cohort study have been conducted to identify the real life determinants. Besides, there may be recall bias on recalling duration of illness, self reporting of patients regarding sensitivity of the topic under the study. Above all, the study is institution based cross-sectional study it might be difficult to generalize to the whole population

\section{Conclusion}

The study reveals that, discloser rate of women to sexual partners was $72.9 \%$. The main means of knowing HIV status was during sickness, pregnancy and marriages. Being aware of sexual partners HIV status, receiving counseling, Duration on ART, having children and relationship before HIV test; are the major determinants of HIV status discloser. On the other hand, fear of stigma, fear of divorce, fear of rejection, fear of fear of sexual violence and others such as psychological discrimination was the commonest reasons for not disclosing their status to their partners. The benefit of HIV status discloser were freedom to ART follow up, free of anxiety, freedom to use condom and getting special support.

\section{Recommendation}

Based on the study finding the following recommendations are drown to enhance HIV status disclosure and benefit women from status disclosure thereby to contribute to the fight against HIV eradication

- Health care providers specially working on Hawassa university comprehensive specialized hospital ART clinic should provide intense counseling on the benefit of HIV status Disclosure

- Hawassa university comprehensive specialized hospital ART clinic needs to intervene community as whole in order to bring about wide spread change in behavior ,Beliefs that govern people's attitudes,. Hence reduce negative attitudes towards discloser.

- To increase the generalizability of the study we recommend community based prospective study Authors'

\section{Contribution}

LB wrote the proposal, participated in data collection, analyzed the data and drafted the paper. BD and JE participated by revising and approving the proposal, data analysis and revised subsequent drafts of the paper. BD has been prepared the manuscript. All authors read and approved the final manuscript.

\section{References}

1. Amy M, Claudian G, Scott M, Susanne M (2003) Outcomes of HIV Sero status discloser among women in developing countries. Implication for prevention of mother to child transmission program.

2. Kathleen S, Joachim V, Dongmai L (2011) Female discloser of HIV positive sero-status to sex partners: A two city study. Women Health 50: 506-526.

3. Anthony B, Anne R, Anne C, Susan A, Brenda T, et al. (2011) Discloser of HIV test result by women to their partners following antenatal HIV testing. BMC 15: 63.
4. Clarke T, Gibson R, Barrow G, James S, Abel W (2010) Disclosure of HIV status among HIV Clinic attendees in Jamaica. West Indian med J 59: 445-449.

5. Jamilla A, Mwanga B (2012) HIV Sero Status Disclosure and Associated Factors Among People Living with HIVIAIDS Attending a Care and Treatment Centre in Kisarawe District Hospital, Tanzania. Muhimbili University of Health and Allied Sciences.

6. Yaya I, Saka B, Landoh D, Patchil P, Patassia A, et al. (2015) HIV status discloser to sexual partner among people with HIV AIDS on ART at Sokode regional hospital Togo. PLoS One 10: e0118157.

7. Ndayala P (2014) Predictors of HIV self disclosure to sexual partners by Seropositive adults in informal settlements: A case of Central division, Nairobi County, Kenya. Kenyatta University Institutional Repository.

8. Shamu S, Zarowsky C, Sheer T, Temmerman M, Abrham N (2014) Intimate partner violence after disclosure of HIV test results among pregnant women in Harare, Zimbabwe. PLoS One 9: e109447.

9. Kebede D, Wassie L, Yismaw M (2004) Determinants and outcomes of discloser HIV sero positive status to sexual partner among women in Mettu and Gore towns of Illibabur zone south west Ethiopia Health. Ethiopian Journal of Health Development 19: 126-131.

10. Kebede D, Kiole W, Mekitre W, Alemayehu A (2007) Discloser experience and associated factors among HIV positive men and women clinical services in south west Ethiopia. BMC Public Health 8: 81.

11. Hailesilase B, Worku A, Melkamu B, Gebrmariyam W (2015) HIV positive status disclosure and associated factors among HIV positive adults in axum health facilities, Tigray, Northern Ethiopia. Science Journal of Public Health 3: 61-66.

12. Daniel A, Sebsibe T, Mulat A, Zelalem B (2014) HIV sero-status disclose associated factor among HIV positive pregnant women attending ANC service in North West Ethiopia. International Journal of Infection Control 10: 4-4.

13. Fekadu $\mathrm{H}$, Addise M, Mevre $\mathrm{H}$ (2014) Sero-status discloser and condom use among PLWHA on ART in Asseue town health facility. J AIDS Clin Res 6: 414.

14. WHO (2014) Gender dimensions of HIV status disclosure to sexual partner: Rate barriers and outcomes. WHO, Geneva, Switzerland.

15. Nebyu M (2007) Being a women and living with HIVIAIDS: Socio cultural and economic problems attending women living with HIVIAIDS in Aradasubcity. $J$ AIDS Clin Res.

16. Brown U (2013) In Ethiopia HIV discloser is low. Brown University.

17. Kuila ES, Damian DJ, Msuya SE (2013) Peredictors of HIV seropositive stutus disclosure to partner among pregnant women in morocco, Tanzania. BMC public health 13: 433.

18. Medha V, Linda M, Sara C, Abbas T, Ruth S, et al. (2014) HIV -disclosure, social support and depression anon HIV infected African women living in rural southeastern united states. AIDS education and prevention 23: 78-90

19. Longinetti E, Santacatterina M, El-Khatib (2014) Gender perspective of risk factors associated with disclosure of HIV status, cross-sectional study in Soweto, South Africa. PLoS One 9: e95440.

20. Adam BD, Elliott R, Husbands W, Murray J, Maxwell J (2008) Effects of the criminalization of HIV transmission in Cuerrier on men reporting unprotected sex with men. Canadian Journal of Law and Society 23: 143-159.

21. Bourne A (2009) Relative safety II: Risk and unprotected anal intercourse among gay men with diagnosed HIV. Sigma Research, London.

22. Human Rights (2007) Watch hidden in the mealie meal: Gender-based abuses and women's HIV treatment in Zambia. HRW.

23. Stutterheim SE, Bos AER, Pryor JB, Brands R, Liebregts M, et al. (2011) Psychological and social correlates of HIV status disclosure: The significance of stigma visibility. AIDS Educ Prev 23: 382-392.

24. Rodkjaer L, Sodemann M, Os tergaard L, Lomborg K (2011) Disclosure decisions: HIV-positive persons coping with disease-related stressors. Qualitative Health Research 21: 1249-1259. 